\title{
Biomaterial Strategies to Bolster Neural Stem Cell-Mediated Repair of the Central Nervous System
}

\author{
Giancarlo Tejeda ${ }^{a, b}$ Andrew J. Ciciriello ${ }^{a, b}$ Courtney M. Dumont ${ }^{a, b}$ \\ aDepartment of Biomedical Engineering, University of Miami, Coral Gables, FL, USA; ${ }^{b}$ Biomedical Nanotechnology \\ Institute at the University of Miami (BioNIUM), University of Miami, Miami, FL, USA
}

\section{Keywords}

Neural stem cells · Biomaterials · Regenerative medicine

\begin{abstract}
Stem cell therapies have the potential to not only repair, but to regenerate tissue of the central nervous system (CNS). Recent studies demonstrate that transplanted stem cells can differentiate into neurons and integrate with the intact circuitry after traumatic injury. Unfortunately, the positive findings described in rodent models have not been replicated in clinical trials, where the burden to maintain the cell viability necessary for tissue repair becomes more challenging. Low transplant survival remains the greatest barrier to stem cellmediated repair of the CNS, often with fewer than $1-2 \%$ of the transplanted cells remaining after 1 week. Strategic transplantation parameters, such as injection location, cell concentration, and transplant timing achieve only modest improvements in stem cell transplant survival and appear inconsistent across studies. Biomaterials provide researchers with a means to significantly improve stem cell transplant survival through two mechanisms: (1) a vehicle to deliver and protect the stem cells and (2) a substrate to control the cytotoxic injury environment. These biomaterial strategies
\end{abstract}

can alleviate cell death associated with delivery to the injury and can be used to limit cell death after transplantation by limiting cell exposure to cytotoxic signals. Moreover, it is likely that control of the injury environment with biomaterials will lead to a more reliable support for transplanted cell populations. This review will highlight the challenges associated with cell delivery in the CNS and the advances in biomaterial development and deployment for stem cell therapies necessary to bolster stem cell-mediated repair.

(c) 2021 S. Karger AG, Basel

\section{Introduction}

Damage to the central nervous system (CNS) can lead to cognitive, motor, and sensory dysfunction, as well as impaired function of major organs. Differences in structure, cellular composition, endogenous electrical currents, and biochemical gradients exist both within and across the brain and spinal cord, making it challenging to study and understand post-injury pathophysiology [Yoon et al., 2017; Xuan et al., 2019; Uchida et al., 2020]. Despite the differences that exist within and across the brain and spinal cord, there are similarities that can be 


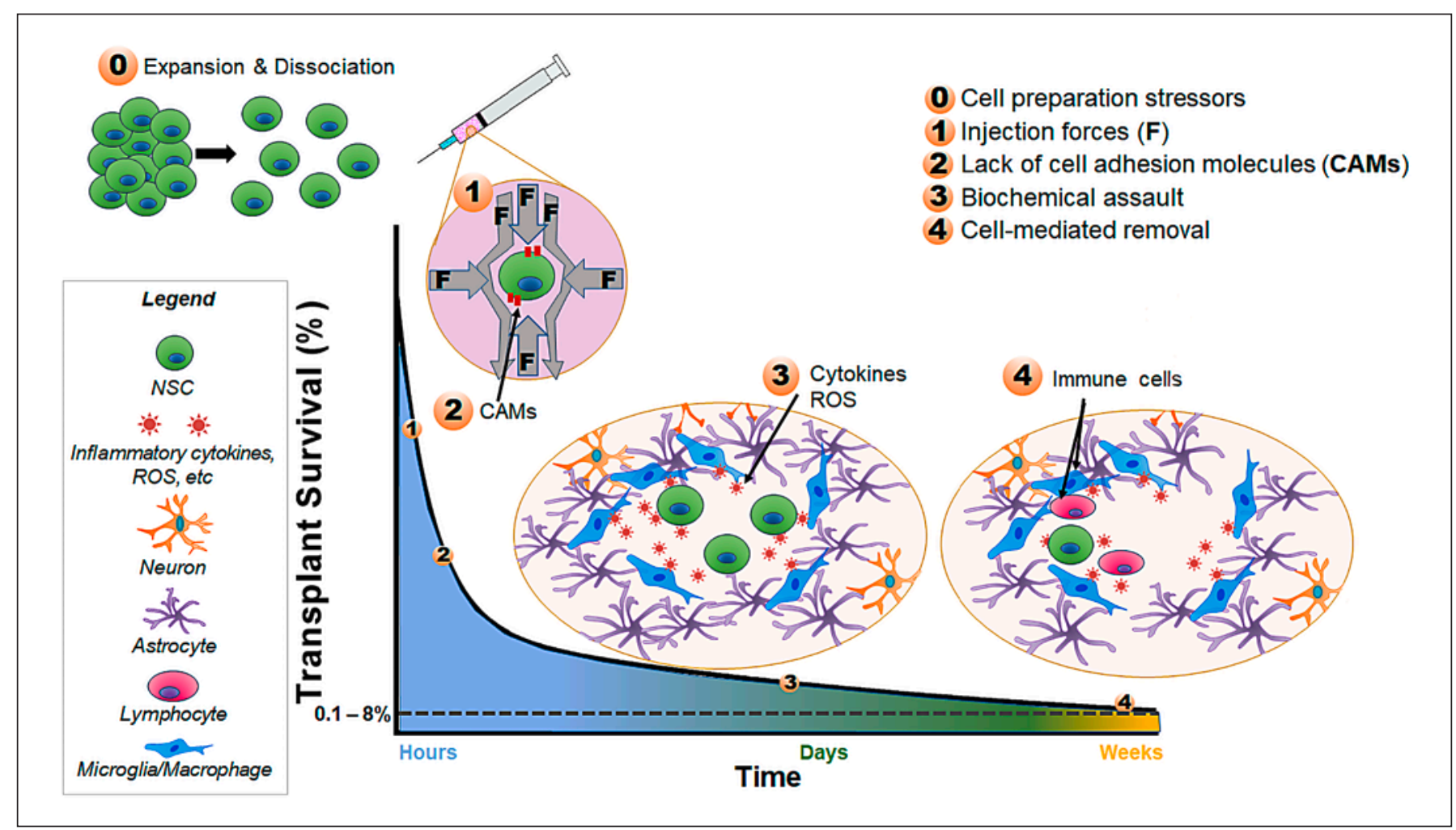

Fig. 1. Cell transplant survival is highly dependent on several parameters that need to be considered when working with stem cellbased therapies. Prior to transplantation, cell expansion and subsequent dissociation into single cell suspensions can stress the cells, resulting in a decrease in viability $(0)$. Once loaded into a syringe, forces (F) experienced during injection (1) and a lack of sites for cell attachment (2) can lead to further cell death. After injection, the transplanted cells are subjected to a highly inflammatory microenvironment, becoming the target of a biochemical as-

observed in these tissues following injury to the CNS. The primary injury results in loss of neurons and glia, as well as injury to the vasculature supplying the tissue. Following primary injury, the body attempts to clear debris and prevent infection through mobilization of neutrophils, microglia, and macrophages to the injury. The local immune response leads to increased release of proinflammatory factors, resulting in further tissue damage, known as the secondary injury. As part of this response, astrocytes and fibroblasts deposit extracellular matrix (ECM) and align to create barriers known as the glial and fibrotic scars, respectively, to prevent further inflammation-mediated damage, but these barriers also limit axonal elongation through the injury. Furthermore, intact axon tracts retract and demyelinate further from the injury site, making it more challenging to regenerate the lost tracts. sault from pro-inflammatory cytokines and reactive oxygen species (3). Transplanted cells may also experience immune cell-mediated removal by infiltrating lymphocytes and macrophages (4). Altogether, these forces and environmental-based stressors can result in a precipitous drop in transplant survival to $0.1-8 \%$ survival, severely limiting their regenerative potential. The number associated with transplant challenge (1-4) has been superimposed on the timeline to indicate the presumed contribution to cell death if that challenge is not addressed.

There are currently several tissue engineering approaches that seek to address specific facets of the CNS injury pathophysiology [Dumont et al., 2016], as well as many cell-based approaches to promote tissue plasticity and repair [Ruff et al., 2012]. Neural stem cells (NSCs) offer one promising means to address both the post-CNS injury pathophysiology and promotion of tissue plasticity and regeneration. NSCs are able to proliferate and differentiate, leading to repopulation of the damaged tissue with CNS cells [Tetzlaff et al., 2011; Iyer et al., 2017; Bruggeman et al., 2019], aiding with tissue repair. Support from endogenous cells is also enhanced by transplanted NSCs that are capable of secreting neurotrophic factors and ECM components [Hawryluk et al., 2012; Laterza et al., 2013; Willis et al., 2020] necessary for local cell recruitment and repair. NSCs can also modulate pro-inflammatory immune cells toward more pro-regenerative pheno- 
Table 1. Biomaterials used for cell delivery to the CNS can impact several transplant outcomes, including survival, attachment, and differentiation

\begin{tabular}{|c|c|c|c|c|c|c|}
\hline Biomaterial & Cell type & Injury model & $\begin{array}{l}\text { Sur- } \\
\text { vival }\end{array}$ & $\begin{array}{l}\text { Attach- } \\
\text { ment }\end{array}$ & $\begin{array}{l}\text { Differen- } \\
\text { tiation }\end{array}$ & Reference \\
\hline SHIELD & Schwann cells & C5 contusion SCI - rat & $\checkmark$ & $\checkmark$ & & [Marquardt et al., 2020] \\
\hline PEG tubes & Spinal progenitors & C5 hemisection SCI - mouse & $\checkmark$ & $\sqrt{ }$ & $\checkmark$ & [Ciciriello et al., 2020] \\
\hline Collagen scaffold + EGFR-Fab & NSCs & T8 transection SCI - rat & & $\sqrt{ }$ & $\checkmark$ & [Xu et al., 2017] \\
\hline PLGA scaffold & Spinal progenitors & T9/T10 hemisection SCI - mouse & $\checkmark$ & $\checkmark$ & $\checkmark$ & [Dumont et al., 2018a] \\
\hline $\mathrm{RADA}_{16}-\mathrm{IKVAV}$ & NSCs & TBI - rat & $\checkmark$ & $\checkmark$ & & [Cheng et al., 2013] \\
\hline Polyurethane & NSCs & TBI - zebrafish & $\checkmark$ & & $\checkmark$ & [Hsieh et al., 2015] \\
\hline Hyaluronic acid-acrylate & iPSC-NSCs & Stroke - rat & $\checkmark$ & & $\checkmark$ & [Lam et al., 2014] \\
\hline Collagen HA laminin & NPCs & C4 contusion SCI - rats & & & $\checkmark$ & [Geissler et al., 2018] \\
\hline poly(sebacoyl diglyceride)- IKVAVs scaffold & NSCs & T10 transection SCI - rat & $\checkmark$ & $\checkmark$ & & [Gong et al., 2020] \\
\hline Fibrous PLGA-PEG & iNSCs & T10/T11 transection SCI - rat & $\checkmark$ & & & [Liu et al., 2015] \\
\hline poly(2-hydroxyethyl methacrylate) hydrogel & Spinal progenitors & T8 hemisection SCI - rat & $\checkmark$ & & & [Ruzicka et al., 2013] \\
\hline QL6 self-assembling particles & NPCs & C6 contusion SCI - rat & $\checkmark$ & & $\checkmark$ & [Iwasaki et al., 2014] \\
\hline Polyglycolic acid & NPCs & T10-T11 hemisection SCI - rat & $\checkmark$ & & & [Shin et al., 2018] \\
\hline HAMC-rPDGF-A & NSCs & $\mathrm{T} 2$ contusion $\mathrm{SCI}-$ rat & $\checkmark$ & & $\checkmark$ & [Mothe et al., 2013] \\
\hline HA & iPSC-NSCs & Stroke - mouse & $\checkmark$ & & & [Moshayedi et al., 2016] \\
\hline HAMC-RGD/PDGF-A & OPCs & T2 contusion SCI - rat & $\checkmark$ & $\checkmark$ & $\checkmark$ & [Führmann et al., 2016] \\
\hline Fibrin + growth factors & NSCs & T3 transection SCI - rat & $\checkmark$ & & $\checkmark$ & [Lu et al., 2012] \\
\hline Fibrin-heparin + NT3, PDGF, GDNF & NPCs & $\mathrm{T} 2$ contusion SCI - rat & $\checkmark$ & & & [McCreedy et al., 2014] \\
\hline Collagen scaffold + paclitaxel & NSCs & T8 transection SCI - rat & & & $\checkmark$ & [Li et al., 2018] \\
\hline
\end{tabular}

Traumatic injury and disease models were both included in the assessment of biomaterials combined with cell types, which are denoted as indicated in their respective study. NSCs, neural stem cells; NPCs, neural progenitor cells; iPSC, induced pluripotent stem cells; SCI, spinal cord injury; TBI, traumatic brain injury; T, thoracic; C, cervical.

types [Bonnamain et al., 2012; Nazmi et al., 2014; Assinck et al., 2017] and remediate excitotoxicity [Assinck et al., 2017]. It is important to note that the benefits attributed to NSCs vary depending on NSC source, isolation and culture methods, donor age, transplantation conditions, and survival capacity [Tetzlaff et al., 2011; Iyer et al., 2017]. In the context of this review, we will use the term NSC to refer to both neural stem and progenitor cell populations isolated from the brain or spinal cord, as well as NSC-like cells derived from induced pluripotent stem cells and embryonic stem cells. A recent review on the techniques for deriving each of these cell populations can be found elsewhere [Tang et al., 2017].

The therapeutic benefits of NSCs are limited by their ability to survive transplantation within the inflammatory injury milieu, as detailed in Figure 1. Specifically, NSC survival is predicated on the transplantation method, transplantation timing, cell sourcing and expansion, and the engraftment microenvironment [Tetzlaff et al., 2011; Iyer et al., 2017]. Location of implantation, cell dose density, and timing are also important influencers of cell survival [Piltti et al., 2013a, 2013b, 2015]. Biomaterials can increase NSC transplant survival and engraftment beyond the traditional means of improving NSC survival outlined above. Indeed, several naturally occurring and synthetic biomaterial options for co-transplantation with NSCs have previously been reviewed [Cooke et al., 2010; Iyer et al., 2017], and we have compiled a list of cell-biomaterial strategies for CNS applications in Table 1. In this review, we will evaluate biomaterial properties that impact NSC survival and engraftment directly, as well as indirectly through environmental remediation with different CNS injury models. Additionally, we later look to expand on cell-biomaterial therapies by reviewing current literature relevant for combinatorial therapies that build on prior biomaterial systems. This section is intended to propose promising technology that could be expanded into larger platforms, relevant for improving stem cell survival and tissue regeneration. 
Fig. 2. Biomaterials are an advantageous base for tissue engineering platforms as they are easily modifiable to obtain properties desirable for the required application. Implant mechanical properties can be modified to be similar to those of native tissues. Prior to implantation, biomaterial implants can be functionalized with various surface residues that can encourage cell adhesion upon implantation, facilitating cell infiltration and tissue repopulation. Tissue repopulation and regeneration rates can also be matched with tunable biomaterial degradation rates. Furthermore, biomaterials can encapsulate or serve as a vehicle for cell transplants, improving their microenvironment. In the injury site, scar attenuation has been observed as the biomaterial implant can provide support for previously open cysts. A biomaterial implant also can serve as a depot for local release of a loaded therapeutic factor that can further modulate the injury environment.

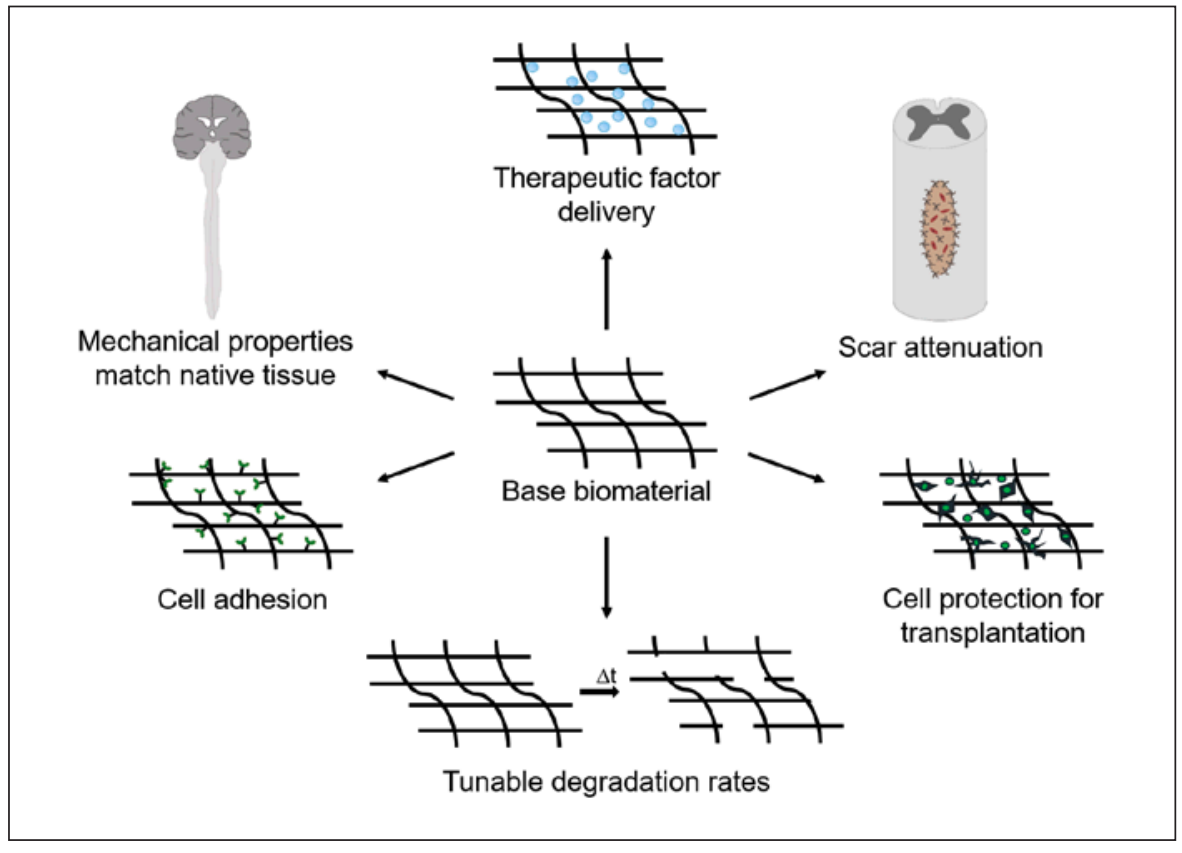

\section{Biomaterials for NSC Delivery and Engraftment}

NSC transplantations are heavily influenced by their local microenvironment, and biomaterial strategies present an easy method for modulation. Biomaterial interventions are advantageous as they often have easily tunable properties, as outlined in Figure 2, that can improve transplantation conditions. Moreover, biomaterials can provide either a vehicle or medium for transplantation that is not present when cells are transplanted alone. This distinction is important, and in several instances of combined biomaterial and NSC strategies, controls for either the biomaterial or the NSCs alone were not present, thus making comparisons between strategies difficult. These studies were still included; however, we denote controls in the text to prevent readers from making assumptions on the effects of the biomaterial and/or NSC alone.

\section{Overcoming Cell Delivery Challenges}

The primary method for cell transplantation is syringe-based injection of the cells at the site of interest. Preparation of the cells prior to transplantation can lead to environmental stressors such as altered gas levels, reduced nutrient availability, and residual dissociation products if preparing single cell suspensions. Cells are then additionally subjected to physical stressors when loaded into the injection syringe. During injection, cells undergo three major mechanical stressors: pressure difference across the cell, shear forces from linear shear flow, and stretching from extensional flow [Aguado et al., 2012]. These conditions can rupture cell membranes, significantly reducing the number of viable cells during transplantation.

Biomaterials that mitigate external forces on cells can reduce force-induced cell death by redistributing shear forces. Load redistribution can be achieved through storage modulus modifications, which describes the ability of a viscoelastic material to store energy elastically under oscillatory strain, and shear-thinning property modifications, which are characterized by a decrease in viscosity when shear force is applied. Strategies to tune these viscoelastic properties and engineer protective biomaterials for cell encapsulation have been reviewed elsewhere [Madl and Heilshorn, 2018]. Alginate hydrogels with varying storage moduli $(0.33-58.1 \mathrm{~Pa})$ were used to observe the effect on the transplantation of different cell populations including human umbilical vein endothelial cells, human adipose stem cells, rat mesenchymal stem cells, and mouse NSCs [Aguado et al., 2012]. Hydrogels with a storage modulus of $30 \mathrm{~Pa}$ resulted in the highest cell viability across all tested cell populations in an in vitro cell injection model. Extensional flow, which causes stretching and deformation as the cells move from the larger diameter of the syringe to the smaller diameter of the needle, was found to be lowest in alginate gels with a 30-Pa storage modulus compared to gels with lower storage moduli. When injected, the hydrogel underwent shear-banding, where the layer of the alginate hydrogel 
near the wall of the needle shear-thins and acts as a lubricant, while the rest of the hydrogel on the inner layers held its form, thus reducing the apparent stress experienced by the suspended cells [Aguado et al., 2012] .

Shear-thinning hydrogels reduce the shear force that the cells experience, which can contribute to a significant loss of viable transplanted cells. Marquardt et al. [2020] built upon prior protective hydrogel strategies [Cai et al., 2015], developing a shear-thinning hydrogel for injectable encapsulation and long-term delivery (SHIELD) that protected Schwann cells during injection and prevented cell reflux, where cells flow out of the injury through the injection site after needle removal. The SHIELD gel included an engineered protein (C7), proline-rich 8-arm polyethylene glycol (PEG), and a thermoresponsive molecule, poly $(\mathrm{N}-$ isopropylacrylamide), allowing for gel deformation under injection forces and reformation after injection. Schwann cells encapsulated in the SHIELD hydrogel and injected into a cervical contusion spinal cord injury (SCI) model experienced a 7.4-fold increase in Schwann cell viability compared to cells injected in saline at $48 \mathrm{~h}$ post-transplant and 12-fold increase in Schwann cell viability at 4 weeks post-transplant. Increased Schwann cell survival with SHIELD hydrogel use additionally resulted in greater functional recovery compared to Schwann cells in saline [Marquardt et al., 2020]. While Schwann cells, not stem cells, were used in this study, they experience many of the same viability problems in transplantation as stem cells, rendering the SHIELD hydrogel a highly promising biomaterial delivery system that can be applied to NSC transplantations. Developing a biomaterial that is supportive and protective of NSCs during transplantation is crucial for allowing NSCs to maximize their therapeutic potential.

\section{Supporting Cell Adhesion}

Once transplanted into the injury, surviving cells face a new set of challenges for their long-term survival. Cells transplanted in media or saline lack physical support, leading to apoptosis in the absence of cell adhesion in a process known as anoikis [Cooke et al., 2010; Mitrousis et al., 2018]. Rho and ROCK signaling inhibitors reduced anoikis in NSCs transplanted into an uninjured mouse brain [Koyanagi et al., 2008], suggesting possible pharmaceutical options to circumvent anoikis. Biomaterials can also reduce anoikis by providing a substrate for transplanted cells to attach to, thereby limiting anoikis-attributable cell death due to lack of support [Marquardt and Heilshorn, 2016]. Biomaterials can be functionalized with ECM proteins, ECM-based peptide motifs, or other cell adhesion molecules to facilitate cell attachment. Several

Biomaterials to Support Cell-Mediated Repair of the CNS
ECM proteins and peptides within biomaterials bind to the $\beta 1$ integrin on NSCs, leading to an upregulation of MAPK signaling, activating survival and proliferation pathways [Stukel and Willits, 2015].

Hydrogels like the self-assembling peptide, $\mathrm{RADA}_{16}$, have shape-memory properties where they can organize into a pre-programmed shape or morphology, even after shear-thinning. $\mathrm{RADA}_{16}$ also includes the laminin-based IKVAV peptide motif for encapsulated NSC attachment [Cheng et al., 2013]. Cells suspended in RADA ${ }_{16}$ were injected into a traumatic brain injury model in rats, and immunohistochemical analysis showed significant proliferation and greater neuronal differentiation compared to the hydrogel without IKVAV. RADA 16 gels can also be functionalized with FGL, a motif from neural cell adhesion molecule (NCAM), to serve as a neuroprotective hydrogel in NSC-biomaterial implants [Wang et al., 2015]. A similar approach was used to deliver oligodendrocyte progenitor cells (OPCs) [Führmann et al., 2016] or NSCs [Mothe et al., 2013] in media or a hyaluronic acid/methyl cellulose (HAMC) copolymer hydrogel functionalized with the fibronectin-based peptide, RGD, and platelet derived growth factor (PDGF). Cell survival and migration were increased in both OPCs and NSCs in the HAMCRGD/PDGF hydrogel compared to the cells transplanted in media alone. Other peptides derived from NCAM are also being investigated to selectively limit adhesion to CNS-derived cells and to facilitate increased neuronal differentiation of stem cells [Xu et al., 2014]. Another approach employed is the use of antibodies and antigen binding factors to bind to epidermal growth factor receptors (EGFRs) expressed on the surface of NSCs. A scaffold functionalized with an EGFR antibody was designed to promote NSC adhesion to the scaffold and direct neuronal differentiation. Both NSCs and neurons were increased in the EGFR-functionalized scaffold compared to the scaffold without the EGFR antibody [Xu et al., 2017]. Biomaterials as a vehicle for cell transplantation can significantly limit anoikis, thereby improving survival, but they can also be used to provide greater control over the cell populations that attach to the substrate and to guide stem cell differentiation. These combined benefits of biomaterial adhesion sites for both transplanted and endogenous cell populations can work synergistically to improve the regenerative potential of transplanted cells within the biomaterial.

\section{Mimicking Biomechanical Properties}

Biomaterial mechanical properties are not just important for injection, but also need to be designed for the 
specific tissue and cell types of interest. Healthy and diseased tissues in the CNS have a broad range of stiffnesses that can significantly alter cell phenotypes, and this is reflected with biomaterial-cell transplants [Barnes et al., 2017]. In particular, biomaterial stiffness can impact NSC proliferation and differentiation [Stukel and Willits, 2015, 2018]. Biomaterial stiffness can also impact the pathophysiology that limits tissue repair after CNS injury, including cell infiltration, inflammation, scar formation, and cavitation [Dumont et al., 2015, 2016]. As the injury pathophysiology can directly impact NSC survival, proliferation, and fate, it is thought that biomaterial regulation of these processes can indirectly impact NSCs and their responses.

In the context of CNS repair, it is important that the biomaterial storage modulus is comparable to that of native brain or spinal cord tissue $(0.5-10 \mathrm{kPa})$ [Stukel and Willits, 2015, 2018; Karimi et al., 2017]. NSCs encapsulated in a polyurethane (PU) thermoresponsive hydrogel with varying storage moduli (30\% PU1: 4,000 Pa, 25\% PU1: 1,100 Pa, 30\% PU2: 2,400 Pa, and 25\% PU2: $680 \mathrm{~Pa}$ ) were transplanted into zebrafish embryos after traumatic brain injury [Hsieh et al., 2015]. NSCs suspended in the $25 \%$ PU2 hydrogels that had a storage modulus of $\sim 680$ $\mathrm{Pa}$ led to increased proliferation and neuronal differentiation of the transplanted NSCs, while the other PU hydrogels with greater storage moduli led to greater glial differentiation. The 25\% PU2 hydrogel also increased functional recovery measured by the spontaneous coiling rate of the embryos $24 \mathrm{~h}$ post fertilization [Hsieh et al., 2015].

Biomaterials with optimized biomimetic mechanical properties can also help modulate scarring in the injury [Moshayedi et al., 2016]. Hyaluronic acid (HA) hydrogels with storage moduli of 100,350 , and 1,000 Pa were injected into a stroke cavity. HA hydrogels with 100 Pa storage modulus had the least hydrogel volume remaining 2 weeks post-injection and had the largest infarct area compared to all other tested conditions. Conversely, HA hydrogels with 350 and 1,000 Pa storage moduli had a significant volume remaining 2 weeks post-injection at the stroke site; however, the $350 \mathrm{~Pa}$ hydrogel resulted in the smallest remaining infarct area, suggesting improved tissue sparing and ingrowth. The $350 \mathrm{~Pa}$ hydrogel also improved NSC survival, proliferation, and differentiation in a cell adhesion molecule and conjugated growth factordependent manner. Interestingly, conditions that fostered the greatest survival and proliferation led to increased astrocytic differentiation among the transplanted cells [Moshayedi et al., 2016]. Similarly, a reduction in scarring, increased tissue sparing, increased stem cell survival, and improved neuronal differentiation have been found with low storage modulus gelatin methacrylate [Fan et al., 2018], collagen HA laminin [Geissler et al., 2018], and PEG [Ciciriello et al., 2020] hydrogels when transplanted after SCI.

Mechanical properties are not solely limited to material stiffness, but are also informed by the micro- and macro-structure of an implant. Biomaterial pore size and density can reduce the bulk mechanical properties of an implant to more closely mimic that of the CNS tissue, as observed previously with PEG hydrogel tubes [Dumont et al., 2019]. The resulting mechanical shift and presence of a physical space for cell infiltration has been well documented to impact inflammation after injury in several tissue types [Madden et al., 2010; Underwood et al., 2011], including the CNS, where porosity also limits scar formation and cavitation [De Laporte et al., 2009; Dumont et al., 2016; Margul et al., 2016; Nih et al., 2017, 2018; Park et al., 2018a]. Pores within scaffolds can also provide a space for cell loading and delivery to the injured CNS [Dumont et al., 2018a] or provide a depot for delayed stem cell transplantation [Ciciriello et al., 2020] following biomaterial-mediated remediation of the injury site.

Locally, pore size and interconnectivity have significant effects on cell adhesion, phenotype, proliferation, differentiation, and nutrient supply. Biomaterials with smaller pore sizes and greater porosity have more surface area for cell adhesion, a cell process necessary for survival, proliferation, and differentiation. Pore size can also impact cell phenotype for infiltrating immune populations. Pore sizes of $30-40 \mu \mathrm{m}$ lead to a shift in macrophage phenotype toward a pro-regenerative expression profile, while also decreasing the formation of foreign body giant cells and increasing angiogenesis [Madden et al., 2010; Underwood et al., 2011]. Pore size is also an important determinant of oxygen and nutrient penetration through a biomaterial. Low porosity can limit the amount of oxygen and nutrients within a space, which will limit cell proliferation and ingrowth in vivo [O'Brien et al., 2005; Loh and Choong, 2013]. Interconnectivity of a porous biomaterial allows for improved cell infiltration within the scaffold, and for nutrients and oxygen to permeate throughout. Interconnected pore spacing is also relevant for vessel infiltration that will be necessary for long-term nutrient supply to the area. Interconnected nodes should be approximately $60 \mu \mathrm{m}$ apart to support vascularization of the biomaterial [Sieminski and Gooch, 2000]. Ultimately, the pore size, density, and interconnectivity will impact bulk mechanical properties that must be balanced 
with the local impacts of porosity, namely nutrient transport and cellular responses to facilitate enhanced transplant survival and regeneration. Furthermore, porous biomaterials can serve as a delivery platform for lentiviral-mediated overexpression of a protein of interest [Park et al., 2018a; Smith et al., 2020]. This viral depot can combinatorially work with cell delivery to improve NSC transplantation strategies. Inclusion of biomimetic mechanical properties for biomaterials is becoming increasingly important to target both the endogenous tissue response and to provide a suitable microenvironment for NSCs that can drive cell survival and neuronal differentiation.

\section{Combinatorial Strategies to Support Stem Cell-Mediated Repair}

Biomaterial-based technologies have advanced significantly in their regenerative abilities, and have become ubiquitous throughout almost all of tissue engineering. Often times, they serve as platforms for therapeutic delivery with highly tunable properties that are advantageous for controlling local release of growth factors and drugs. Additionally, they can serve as a platform for delivering stem cells by offering numerous protective roles to increase survival, as highlighted throughout this review. With that in mind, therapeutic and cell delivery biomaterial platforms are often thought of as two independent strategies. Individually, both demonstrate success in their therapeutic goals, but combining with other strategies could result in further synergistic gains to fulfill the need for improved transplant survival and regeneration. Altogether, incorporating seemingly independent approaches into one technique will result in a robust stem cell delivery platform that has the opportunity to be broadly applicable beyond CNS repair.

\section{Engineering Vascular Support}

Stem cell differentiation and behavior is highly dependent on the local microenvironment, known as the stem cell niche [Morrison and Spradling, 2008; Ferraro et al., 2010]. It is common for stem cell niches throughout the body to include high-density vascular networks, as they are responsible for delivering oxygen and nutrients necessary for differentiation and proliferation [Morrison and Spradling, 2008; Putnam, 2014]. Endothelial cells (ECs) are an important structural component, and the primary cell type, of blood vessels that also play an important role in angiogenesis. In the CNS, the subventricular zone

Biomaterials to Support Cell-Mediated Repair of the CNS
(SVZ) is one example where NSCs are in close contact with ECs. It has been shown that neurogenesis of SVZ NSCs is directly dependent on their distance away from resident vasculature [Shen et al., 2008; Tavazoie et al., 2008]. Furthermore, co-culturing ECs with cerebral cortex NSCs from embryonic day 10-11 (E10-11) in vitro in two-dimensional (2D) transwell plates increases NSC self-renewal and neurogenesis [Shen et al., 2004; Sun et al., 2010]. Other in vitro models attempting to recreate the NSC niche using either static or fluid flow 2D cell culture setups have shown that signaling molecules released from cerebral microvascular ECs further support E10-11 and adult SVZ NSC differentiation and fate [Shen et al., 2004; Dumont et al., 2017, 2018b]. Conversely, postnatal day 1 (P1) [Li et al., 2006] and E14 [Roitbak et al., 2008] NSCs also offer a protective role for ECs when in co-cultures against ischemic conditions with HIF-1 $\alpha$ and VEGF signaling, further highlighting the close relationship between the two cell types. Moreover, co-transplantation of bovine pulmonary microvascular ECs and cortex-derived ischemia-induced adult NSCs has been shown to increase NSC survival at 5 days and 28 days after ischemic stroke [Nakagomi et al., 2009]. Of the surviving NSCs and their progeny, approximately $3 \%$ gave rise to $\mathrm{NeuN}^{+}$neurons, a relatively low percentage, but significantly more than NSCs transplanted alone. Applying the advantages of in vitro co-culturing, niche modeling, and early co-transplantation studies to hydrogel-based cell transplantations could present an effective strategy for improving NSCmediated regeneration. While there is currently minimal work with in vivo co-transplantations in hydrogel networks, feasibility of NSC/EC co-spheroids encapsulated into an injectable gelatin-based hydrogel loaded with human mesenchymal stem cells (hMSCs) and implanted into a Sprague-Dawley rats [Han et al., 2019] and with GFP NSCs from P1 transgenic GFP mice and brain ECs into a macroporous polylysine-PEG hydrogel [Ford et al., 2006] demonstrated improved angiogenesis. Advantages from an NSC standpoint were not investigated in either study, but it is not unreasonable to think that the NSCs would benefit from improved vascular formation as the local NSC niche is regulated by distribution of signals present in blood circulation [Goldberg and Hirschi, 2009; Otsuki and Brand, 2017; Karakatsani et al., 2019].

Acellular alternatives to establish a vascularized, nichelike implantation site that could be used for NSC delivery have been explored with poly(lactic-co-glycolic acid) (PLGA) [Bible et al., 2012], HA [Nih et al., 2017], and HA-heparin [Nih et al., 2018] microparticle networks that release VEGF. Each study demonstrated robust re- 
vascularization; however, vessel patency was significantly improved with HA-heparin microgels. In particular the density of the VEGF within the microgel network was an important design characteristic with many of the particles devoid of VEGF and a subset of particles loaded with a high VEGF density [Nih et al., 2018]. Without the careful design of VEGF loading parameterization, it was found that high-density microvascular structures were present, but resulted in increased inflammation and astrogliosis [Bible et al., 2012], rather than the increased tissue repair and functional recovery observed in the VEGF densitycontrolled HA-heparin biomaterial [Nih et al., 2018]. Only one of these studies explored their biomaterial for NSC transplantation; however, due to hypervascularization and increased inflammation, there was an increase in astrocyte differentiation [Bible et al., 2012]. In each of these studies a network of biomaterial microspheres was loaded into the injury, thus generating a porous biomaterial network. As described earlier, the porosity of the biomaterial will impact nutrient transport, vascular cell infiltration, and vessel formation [Loh and Choong, 2013]. Future studies should look to combine the benefit of angiogenic materials to generate an environment that is supportive of subsequent NSC transplantation.

\section{Mediators of Transplant Differentiation}

Biomaterial composition and release of bioactive molecules, such as neurotrophins, readily impact NSC differentiation, as reviewed elsewhere [Wang and SakiyamaElbert, 2019]. The effects of these factors on NSC differentiation can be challenging to parse from proliferation and survival, as differentiation is not possible without survival. Aside from biochemical cues, researchers have also tried to control the resulting NSC progeny through cell sorting for desirable progenitor or precursor populations [Hu et al., 2012; Sher et al., 2012; Wang et al., 2013; Vadivelu et al., 2015; Butenschon et al., 2016], delivering micro-tubule stabilizing drugs [Li et al., 2018], and preconditioning NSC populations with support cells known to increase neurogenesis [Lowry et al., 2008]. It is unclear if pre-conditioning or selection of NSCs has an impact on differentiation, or if the injury site is primed to promote survival of select NSC phenotypes. This dichotomy between increased survival and ensuring desirable cell phenotypes is best observed from a study using HA hydrogels with varying concentrations of brain-derived neurotropic factor (BDNF), and bone morphogenic factor-4 (BMP4) [Moshayedi et al., 2016]. In this study, the HA hydrogel with elevated BMP-4 promoted increased survival of transplanted cells; however, it resulted in increased astro- glial differentiation. HA with lower BMP-4 concentrations and elevated BDNF resulted in lower survival, but within the surviving population, there was increased neuronal differentiation, suggesting an inverse relationship between survival rates and tissue repopulation. It has been suggested that this inverse relationship mimics brain development during which some neurons are selectively culled. As neurons are formed, they begin to elongate axons and are highly susceptible to apoptosis [Dekkers et al., 2013]. During this process, caspases responsible for triggering apoptosis can also produce mitogens that stimulate NSC proliferation [Bergmann and Steller, 2010]. One way to address survival and differentiation challenges is to co-deliver neural progenitors with V2a spinal interneurons to the injured spinal cord, which improves transplant integration with intact circuitry leading to improve functional outcomes [Zholudeva et al., 2018]. More research is needed to explore transplantation phenotypes and differentiation into specific neuron populations. Technologies to evaluate integration of cell transplants with intact circuitry are also advancing [Adler et al., 2017; Anzalone et al., 2018] and provide researchers with more opportunities to validate functionality of differentiated cell transplants.

\section{Immune-Modulating Therapeutics}

Design of hydrogels for local drug release has been investigated heavily for many tissue engineering applications [Sharpe et al., 2014; Li and Mooney, 2016], including CNS injuries [Piantino et al., 2006; Kang et al., 2009; Nih et al., 2018]. Without physical and/or biochemical support, stem cell transplant viability remains low, often times below 5\% 1 week post-transplantation in immunocompetent rodents [Parr et al., 2008; Tetzlaff et al., 2011; Cusimano et al., 2012; Mothe et al., 2013; Butenschon et al., 2016; Iyer et al., 2017]. Hydrogels alone have some capacity for immunomodulation [Singh and Peppas, 2014; Adu-Berchie and Mooney, 2020]. For example, in SCI models, both fibrin and high-molecular-weight HAbased hydrogel implants can inhibit glial scar formation when implanted immediately after injury [Taylor et al., 2006; Khaing et al., 2011; Zuidema et al., 2018], while HA can additionally reduce astrocyte proliferation through direct binding to cell surface receptors, like CD44, thus limiting inflammation [Back et al., 2005].

Biomaterial-mediated immune modulation can be further enhanced with sustained therapeutic release, whereby a local injury microenvironment can be significantly altered. With that in mind, immune modulation timing post-SCI is highly dependent on the desired target, 
as different circulating cells and inflammatory mediators peak in concentration in the hours, days, and weeks postinjury [Donnelly and Popovich, 2008]. The dichotomy of damage versus recovery must be considered when deciding delivery timing for immune-modulating therapies, but it is important to note that full ablation of immune populations is often detrimental as inflammatory cells and mediators have regulatory roles in neuroplasticity [Schwab et al., 2014]. Timing delivery to maximize regulatory roles while limiting damage due to sustained exposure is crucial, further complicating immune modulation. A common target for immune modulation is infiltrating macrophages, as they are a well-studied cell population prevalent in many injury paradigms. Macrophages and microglia, the resident CNS macrophage, exist on a nuanced spectrum of phenotypes that are often simplified to being pro-inflammatory (M1) or pro-regenerative (M2) [Mosser and Edwards, 2008; Novak and Koh, 2013]. Microglia often accumulate quickly (hours) after injury, as they are resident to the CNS, and sustain their presence into the chronic window while macrophages often peak in concentration at 1-2 weeks with a second wave of macrophage infiltration reported to occur at 8 weeks, well into the chronic injury [Donnelly and Popovich, 2008; Beck et al., 2010; Dumont et al., 2016]. Anti-inflammatory factors, including those from the interleukin (IL) family of cytokines including IL-4, IL-10, IL-13, and IL-33, are important for polarization to the M2 phenotype [Gadani et al., 2015; Liu et al., 2016; Lobo-Silva et al., 2016; Margul et al., 2016; Mori et al., 2016; Park et al., 2018a, 2018b; Ciciriello et al., 2020; Smith et al., 2020]. Slow release of exogenous IL-10 from a biomaterial significantly improves its retention at the injury, lasting across acute to chronic time scales, compared to bolus IL10 injections, and further reduces M1-like presence, resulting in a more pro-regenerative site [Boehler et al., 2014; Gower et al., 2014; Hellenbrand et al., 2019]. Similarly, immune-suppressing corticosteroids, like methylprednisolone, can be encapsulated into injectable biomaterials and slowly released over the course of days postinjury [Pritchard et al., 2011; Slotkin et al., 2016], but their broad-acting immune suppression has led to controversy over their actual therapeutic effect compared to potential complications [Cheung et al., 2015; Fehlings et al., 2017].

There has been little investigation into combining stem cells, hydrogels, and immune-modulating therapeutic release as a combination strategy, but their independent successes highlight the potential synergistic reparative effects possible when combining together. With a more hospitable transplantation niche, cell engraftment and survival will improve, resulting in improved regeneration. RNAi knockdown of lipocalin 2 [Braga et al., 2020] or tumor necrosis factor alpha (TNF- $\alpha$ ) antagonistmediated suppression [Wang et al., 2014] delivered immediately after injury in the absence of a biomaterial have both increased NSC survival and engraftment, suggesting the combination of anti-inflammatory therapeutics combined with the benefits of a biomaterial could further improve NSC survival and regeneration. Feasibility of controlling both cell and therapeutic delivery from a biomaterial has been demonstrated outside of the nervous system. While not a hydrogel, a combination therapy using a porous PLGA scaffold to co-deliver islets with IL-33 improved graft survival improving exogenous regeneration while also stimulating endogenous cell populations [Liu et al., 2018]. In situ bone regeneration was also observed when combining injectable gelatin-based hydrogels encapsulated with both MSCs and a small hydrophobic drug called icaritin [Feng et al., 2019].

\section{Nanoparticle Therapeutics to Mitigate Inflammation}

Nanoparticle delivery is taken advantage of throughout tissue engineering [Hasan et al., 2018], with a large number of strategies focused on administration of a therapeutic payload [De Jong and Borm, 2008; Patra et al., 2018]. Alternatively, nanoparticles have also been used to modulate immune responses post-injury. Post-administration, polymeric nanoparticles are taken up by infiltrating immune cells and have the ability to reprogram their responses and traffic them away from the injury, effectively attenuating their response. Negative surfacecharged PLGA nanoparticles bind to circulating immune cells and traffic them to the spleen in numerous CNS injury models [Getts et al., 2012, 2015; Getts, 2014; Park et al., 2019]. Similarly, Papa et al. [2013, 2014] have shown that PEGylated poly(methyl methacrylate) (PMMA) and poly-E-caprolactone nanoparticles were both internalized by pro-inflammatory macrophages and microglia when delivered in a thoracic SCI model. Mice with PLGA bridges implanted within the injured spinal cord that receive daily doses of intravenous PLGA nanoparticles in the first 5 days post-injury were observed to have increased tissue sparing and increased locomotor recovery compared to mice receiving the implant alone [Park et al., 2019]. The combined use of biomaterial approaches in the SCI model suggests that there is a synergy between the materials targeting different aspects of injury pathophysiology. The addition of NSCs could increase tissue regeneration, while the nanoparticles would further mitigate local inflammation that restricts NSC survival to 5\% when 
transplanted within the PLGA bridges without nanoparticles [Dumont et al., 2018a]. Additionally, nanoparticles can be encapsulated into hydrogels for controlled local delivery to an injury model [Papa et al., 2013, 2014; Mauri et al., 2018; Dannert et al., 2019], limiting off-target accumulation. Poly acrylic acid hydrogels can be functionalized with tunable pore sizes for controlling encapsulated PMMA nanoparticle release [Rossi et al., 2013]. Co-encapsulating nanoparticles into a hydrogel with stem cells could be a combinatorially beneficial tissue engineering strategy. A functionalized hydrogel containing both stem cells and nanoparticles could be implanted into an injury site, where the smaller nanoparticles would have a quick, tunable release [Wang et al., 2020] to reprogram pro-inflammatory cytokines that would normally limit transplant survival [Park et al., 2019]. With the immune response attenuated and shifted away from the transplants, more surviving cells would be able to proliferate and differentiate within the hydrogel and eventually repopulate lost or damaged tissue.

Functionalized nanoparticles can also be used to sequester pro-inflammatory cytokines and chemokines themselves, rather than reprogram immune cells. Postinjury, cytokines are involved in a feedback loop where as they are produced, infiltrating leukocytes sense their presence and thus contribute to further inflammation [Rahman et al., 2018]. Disrupting this cycle by decreasing pro-inflammatory cytokine concentrations at the injury could be beneficial from a tissue regeneration standpoint. A comparable strategy is utilized in viral applications where nanotherapeutics can capture foreign antigens and effectively sequestering them away from damaging their targets on the cell and tissue level [Eyckerman et al., 2016]. This targeting strategy can be applied to cytokines through delivery of cytokine-neutralizing antibodies and glycosaminoglycans (GAG) [Zhang et al., 2020]. Antibody-mediated targeting of TNF- $\alpha$ is the basis for blockbuster drug Humira (adalimumab), used for treating various types of arthritis and gastrointestinal diseases. The FDA has approved numerous antibodies that specifically target a wide number of cytokines other than TNF- $\alpha$ including IL-1 $\beta$, IL-17, IL-23, and interferon- $\gamma$ [Lai and Dong, 2016; Zhang et al., 2020]. Antibody binding is specific enough to limit off-target binding, and once bound, they prevent their target from propagating the immune response as they can no longer bind to infiltrating leukocytes. These antibodies can be conjugated to biomaterials and implanted and delivered locally or nanoparticles and delivered intravenously [Friedrich et al., 2014; Lima et al., 2018]. Similarly, GAGs can be conjugated to biomaterial or nanoparticle surfaces to interfere with chemokine binding, thus reducing leukocyte recruitment. GAGs are normally present on immune cell surfaces, and help with coordinating immune response, but introducing exogenous GAGs on a biomaterial implant can effectively distract chemokines from binding to their intended targets [Thompson et al., 2017].

\section{Conductive Biomaterials}

The NSC niche is a complex microenvironment that directly effects NSC differentiation and maturation based on a number of physical and chemical signals [Conover and Notti, 2008; Decimo et al., 2012]. As described previously, proximity to vasculature and ECs plays a large role in directing endogenous NSC fate. Additionally, electrical signals within the niche can significantly alter differentiation and proliferation, as reviewed previously [Bertucci et al., 2019]. Electrical conditions have been controlled in ex vivo NSC culture, demonstrating that stimulation guides migration, promotes differentiation, and improves viability [Li et al., 2008; Kobelt et al., 2014; Du et al., 2018; Zhu et al., 2019]. Applying this strategy when transplanting cells into a CNS injury model could improve their survival and facilitate improved regeneration. Numerous biomaterials have been developed to have electrically conductive properties [Song and George, 2017; Boni et al., 2018; Vandghanooni and Eskandani, 2019]. Polypyrrole-based neural conduits can direct current electric fields and stimulate guided axonal growth [Lee et al., 2009; Durgam et al., 2010; Nguyen et al., 2014]. Other materials including polyaniline, poly $(3,4$-ethylenedioxythipene), and indium phosphide have been used similarly as guidance conduits and doped hydrogels [Boni et al., 2018]. These conduits or doped hydrogels can be used as a cell transplantation platform with potential to improve regenerative outcomes. Combining the benefits that NSCs receive from electrical stimulation with the regenerative and guidance properties of electrically active biomaterials could lead to improved transplant survival, resulting in more robust NSC neural lineage commitment.

\section{Conclusion}

Substantial strides have been made to understand cell delivery requirements and develop new biomaterials that offer support and protection for transplanted stem cells. Biomaterials offer a therapeutically promising platform on their own, but also have the potential for further en- 
hancement of desired transplant outcomes through integration of additional therapeutics, including cell adhesion peptides, trophic cues, biophysical cues, pathophysiology modifying therapies, or dual biomaterial approaches as discussed in the combinatorial section of this review. A well choreographed treatment regime that integrates these different strategies to treat specific hurdles will likely be needed for any biomaterial-stem cell treatment that moves to the clinic. The next major challenge for this area of research will likely be improving our understanding with regards to the necessary timing for administering particular aspects of a treatment strategy. Moreover, the complexity of the injury microenvironment and the variability of NSC phenotypes needs further investigation to maximize the regenerative potential of transplanted stem cells.

\section{Conflict of Interest Statement}

The authors have no conflicts of interest to declare.

\section{Funding Sources}

Funding was provided by the University of Miami Frost Institute of Chemistry and Molecular Sciences Junior Faculty Research Award.

\section{Author Contributions}

G.T., A.J.C., and C.M.D. contributed to all aspects of manuscript preparation.

\section{References}

Adler AF, Lee-Kubli C, Kumamaru H, Kadoya K, Tuszynski MH. Comprehensive Monosynaptic Rabies Virus Mapping of Host Connectivity with Neural Progenitor Grafts after Spinal Cord Injury. Stem Cell Reports. 2017 Jun 06; 8(6):1525-33.

Adu-Berchie K, Mooney DJ. Biomaterials as Local Niches for Immunomodulation. Acc Chem Res. 2020 Sep 15;53(9):1749-60.

Aguado BA, Mulyasasmita W, Su J, Lampe KJ, Heilshorn SC. Improving viability of stem cells during syringe needle flow through the design of hydrogel cell carriers. Tissue Eng Part A. 2012 Apr;18(7囚8):806-15.

Anzalone A, Chacko JV, Nishi RA, Dumont C, Smith D, Shea LD, et al . Feasibility study on mouse live imaging after spinal cord injury and poly(lactide-co-glycolide) bridge implantation. J Biomed Opt. 2018 Jun;23(06):1-6.

Assinck P, Duncan GJ, Hilton BJ, Plemel JR, Tetzlaff W. Cell transplantation therapy for spinal cord injury. Nat Neurosci. 2017 May 01;20(5): 637-47.

Back SA, Tuohy TM, Chen H, Wallingford N, Craig A, Struve J, et al . Hyaluronan accumulates in demyelinated lesions and inhibits oligodendrocyte progenitor maturation. Nat Med. 2005 Sep 01;11(9):966-72.

Barnes JM, Przybyla L, Weaver VM. Tissue mechanics regulate brain development, homeostasis and disease. J Cell Sci. 2017 Jan 2;130(1):71-82.

Beck KD, Nguyen HX, Galvan MD, Salazar DL, Woodruff TM, Anderson AJ. Quantitative analysis of cellular inflammation after traumatic spinal cord injury: evidence for a multiphasic inflammatory response in the acute to chronic environment. Brain. 2010 Feb; 133(Pt 2):433-47.

Bergmann A, Steller H. Apoptosis, stem cells, and tissue regeneration. Sci Signal. 2010 Oct 26; 3(145):re8-re8.
Bertucci C, Koppes R, Dumont C, Koppes A. Neural responses to electrical stimulation in $2 \mathrm{D}$ and $3 \mathrm{D}$ in vitro environments. Brain Res Bull. 2019 Oct; 152:265-84.

Bible E, Qutachi O, Chau DY, Alexander MR, Shakesheff KM, Modo M. Neo-vascularization of the stroke cavity by implantation of human neural stem cells on VEGF-releasing PLGA microparticles. Biomaterials. 2012 Oct; 33(30):7435-46.

Boehler RM, Kuo R, Shin S, Goodman AG, Pilecki MA, Gower RM, et al . Lentivirus delivery of IL-10 to promote and sustain macrophage polarization towards an anti-inflammatory phenotype. Biotechnol Bioeng. 2014 Jun; 111(6):1210-21.

Boni R, Ali A, Shavandi A, Clarkson AN. Current and novel polymeric biomaterials for neural tissue engineering. J Biomed Sci. 2018 Dec 20; 25(1):90.

Bonnamain V, Neveu I, Naveilhan P. Neural stem/progenitor cells as a promising candidate for regenerative therapy of the central nervous system. Front Cell Neurosci. 2012;6: 17.

Braga A, Bandiera S, Verheyen J, Hamel R, Rutigliani C, Edenhofer F, et al . Combination of In Situ Lcn2 pRNA-RNAi Nanotherapeutics and iNSC Transplantation Ameliorates Experimental SCI in Mice. Mol Ther. 2020 Aug 5;28(12):2677-90.

Bruggeman KF, Moriarty N, Dowd E, Nisbet DR, Parish CL. Harnessing stem cells and biomaterials to promote neural repair. Br J Pharmacol. 2019 2019/02/01;176(3):355-68.

Butenschon J, Zimmermann T, Schmarowski N, Nitsch R, Fackelmeier B, Friedemann K, et al . PSA-NCAM positive neural progenitors stably expressing BDNF promote functional recovery in a mouse model of spinal cord injury. Stem Cell Res Ther. 2016 Jan 13;7:11.
Cai L, Dewi RE, Heilshorn SC. Injectable Hydrogels with In Situ Double Network Formation Enhance Retention of Transplanted Stem Cells. Adv Funct Mater. 2015 Jan 13;25(9):1344-51.

Cerqueira SR, Lee YS, Cornelison RC, Mertz MW, Wachs RA, Schmidt CE, et al . Decellularized peripheral nerve supports Schwann cell transplants and axon growth following spinal cord injury. Biomaterials. 2018;177:176-85.

Cheng TY, Chen MH, Chang WH, Huang MY, Wang TW. Neural stem cells encapsulated in a functionalized self-assembling peptide hydrogel for brain tissue engineering. Biomaterials. 2013 Mar 1;34(8):2005-16.

Cheung V, Hoshide R, Bansal V, Kasper E, Chen CC. Methylprednisolone in the management of spinal cord injuries: Lessons from randomized, controlled trials. Surg Neurol Int. 2015 Aug 24;6:142.

Ciciriello AJ, Smith DR, Munsell MK, Boyd SJ, Shea LD, Dumont CM. Acute Implantation of Aligned Hydrogel Tubes Supports Delayed Spinal Progenitor Implantation. ACS Biomater Sci Eng. 2020 Oct 12;6(10):5771-84.

Conover JC, Notti RQ. The neural stem cell niche. Cell Tissue Res. 2008 Jan;331(1):211-24.

Cooke MJ, Vulic K, Shoichet MS. Design of biomaterials to enhance stem cell survival when transplanted into the damaged central nervous system. Soft Matter. 2010;6(20):498898.

Cusimano $M$, Biziato $D$, Brambilla $E$, Donegà $M$, Alfaro-Cervello C, Snider S, et al . Transplanted neural stem/precursor cells instruct phagocytes and reduce secondary tissue damage in the injured spinal cord. Brain. 2012 Feb; 135(Pt 2):447-60.

Dannert C, Stokke BT, Dias RS. NanoparticleHydrogel Composites: From Molecular Interactions to Macroscopic Behavior. Polymers. 2019 Feb 06;11(2):275.
Biomaterials to Support Cell-Mediated Repair of the CNS 
De Jong WH, Borm PJ. Drug delivery and nanoparticles:applications and hazards. Int $\mathrm{J}$ Nanomedicine. 2008 June 06;3(2):133-49.

De Laporte L, Yan AL, Shea LD. Local gene delivery from ECM-coated poly(lactide-co-glycolide) multiple channel bridges after spinal cord injury. Biomaterials. 2009 Apr;30(12):2361-8.

Decimo I, Bifari F, Krampera M, Fumagalli G. Neural stem cell niches in health and diseases. Curr Pharm Des. 2012 Apr 23;18(13):175583

Dekkers MP, Nikoletopoulou V, Barde YA. Cell biology in neuroscience: Death of developing neurons: new insights and implications for connectivity. J Cell Biol. 2013;203(3):385-93.

Donnelly DJ, Popovich PG. Inflammation and its role in neuroprotection, axonal regeneration and functional recovery after spinal cord injury. Exp Neurol. 2008 Feb;209(2):378-88.

Du J, Zhen G, Chen H, Zhang S, Qing L, Yang X, et al . Optimal electrical stimulation boosts stem cell therapy in nerve regeneration. Biomaterials. 2018 Oct;181:347-59.

Dumont CM, Carlson MA, Munsell MK, Ciciriello AJ, Strnadova K, Park J, et al . Aligned hydrogel tubes guide regeneration following spinal cord injury. Acta Biomater. 2019 Mar 1;86:312-22.

Dumont CM, Margul DJ, Shea LD. Tissue Engineering Approaches to Modulate the Inflammatory Milieu following Spinal Cord Injury. Cells Tissues Organs (Print). 2016;202(1-2): 52-66.

Dumont CM, Munsell MK, Carlson MA, Cummings BJ, Anderson AJ, Shea LD. Spinal Progenitor-Laden Bridges Support Earlier Axon Regeneration Following Spinal Cord Injury. Tissue Eng Part A. 2018a Nov;24(21-22): 1588-602.

Dumont CM, Park J, Shea LD. Controlled release strategies for modulating immune responses to promote tissue regeneration. J Control Release. 2015 Dec 10;219:155-66.

Dumont CM, Piselli J, Temple S, Dai G, Thompson DM. Endothelial Cells Exposed to Fluid Shear Stress Support Diffusion Based Maturation of Adult Neural Progenitor Cells. Cell Mol Bioeng. 2018b Apr;11(2):117-30.

Dumont CM, Piselli JM, Kazi N, Bowman E, Li G, Linhardt RJ, et al . Factors Released from Endothelial Cells Exposed to Flow Impact Adhesion, Proliferation, and Fate Choice in the Adult Neural Stem Cell Lineage. Stem Cells Dev. 2017 Aug 15;26(16):1199-213.

Durgam H, Sapp S, Deister C, Khaing Z, Chang E, Luebben S, et al . Novel Degradable Co-polymers of Polypyrrole Support Cell Proliferation and Enhance Neurite Out-Growth with Electrical Stimulation. J Biomater Sci Polym Ed. 2010 Jan 01;21(10):1265-82.

Eyckerman S, Titeca K, Van Quickelberghe E, Cloots E, Verhee A, Samyn N, et al . Trapping mammalian protein complexes in viral particles. Nat Commun. 2016 Apr 28;7(1):11416.

Fan L, Liu C, Chen X, Zou Y, Zhou Z, Lin C, et al Directing Induced Pluripotent Stem Cell Derived Neural Stem Cell Fate with a Three-Di- mensional Biomimetic Hydrogel for Spinal Cord Injury Repair. ACS Appl Mater Interfaces. 2018 May 30;10(21):17742-55.

Fehlings MG, Wilson JR, Harrop JS, Kwon BK, Tetreault LA, Arnold PM, et al . Efficacy and Safety of Methylprednisolone Sodium Succinate in Acute Spinal Cord Injury: A Systematic Review. Global Spine J. 2017 Sep 05;7(3 Suppl 1):116S-37S.

Feng Q, Xu J, Zhang K, Yao H, Zheng N, Zheng $\mathrm{L}$, et al . Dynamic and Cell-Infiltratable Hydrogels as Injectable Carrier of Therapeutic Cells and Drugs for Treating Challenging Bone Defects. ACS Cent Sci. 2019 Mar 27; 5(3):440-50.

Ferraro F, Celso CL, Scadden D. Adult stem cels and their niches. Adv Exp Med Biol. 2010;695: $155-68$.

Ford MC, Bertram JP, Hynes SR, Michaud M, Li Q, Young M, et al . A macroporous hydrogel for the coculture of neural progenitor and endothelial cells to form functional vascular networks in vivo. Proc Natl Acad Sci USA. 2006 Feb 21;103(8):2512-7.

Friedrich EE, Sun LT, Natesan S, Zamora DO, Christy RJ, Washburn NR. Effects of hyaluronic acid conjugation on anti-TNF- $\alpha$ inhibition of inflammation in burns. J Biomed Mater Res A. 2014 May;102(5):1527-36.

Führmann T, Tam RY, Ballarin B, Coles B, Elliott Donaghue I, van der Kooy D, et al . Injectable hydrogel promotes early survival of induced pluripotent stem cell-derived oligodendrocytes and attenuates longterm teratoma formation in a spinal cord injury model. Biomaterials. 2016 Mar 01;83:23-36.

Gadani SP, Walsh JT, Smirnov I, Zheng J, Kipnis J. The glia-derived alarmin IL-33 orchestrates the immune response and promotes recovery following CNS injury. Neuron. 2015 Feb 18; 85(4):703-9.

Geissler SA, Sabin AL, Besser RR, Gooden OM, Shirk BD, Nguyen QM, et al . Biomimetic hydrogels direct spinal progenitor cell differentiation and promote functional recovery after spinal cord injury. J Neural Eng. 2018 Feb 14; 15(2):025004

Getts DR. Editorial to special issue: monocytes in homeostasis and disease. Cell Immunol. 2014 Sep-Oct;291(1-2):1-2.

Getts DR, Martin AJ, McCarthy DP, Terry RL, Hunter ZN, Yap WT, et al . Microparticles bearing encephalitogenic peptides induce Tcell tolerance and ameliorate experimental autoimmune encephalomyelitis. Nat Biotechnol. 2012 Nov 18;30(12):1217-24.

Getts DR, Shea LD, Miller SD, King NJ. Harnessing nanoparticles for immune modulation. Trends Immunol. 2015 Jul 01;36(7):419-27.

Goldberg JS, Hirschi KK. Diverse roles of the vasculature within the neural stem cell niche. Regen Med. 2009 Nov;4(6):879-97.

Gong Z, Lei D, Wang C, Yu C, Xia K, Shu J, et al . Bioactive elastic scaffold loaded with neural stem cells promote rapid spinal cord regeneration. ACS Biomater Sci Eng. 2020 Nov 9; 6(11):6331-43.
Gower RM, Boehler RM, Azarin SM, Ricci CF, Leonard JN, Shea LD. Modulation of leukocyte infiltration and phenotype in microporous tissue engineering scaffolds via vector induced IL-10 expression. Biomaterials. 2014 Feb;35(6):2024-31.

Gunther MI, Weidner N, Muller R, Blesch A. Cell-seeded alginate hydrogel scaffolds promote directed linear axonal regeneration in the injured rat spinal cord. Acta Biomater. 2015;27:140-50.

Han IB, Thakor DK, Ropper AE, Yu D, Wang L, Kabatas S, et al . Physical impacts of PLGA scaffolding on hMSCs: Recovery neurobiology insight for implant design to treat spinal cord injury. Exp Neurol. 2019 Oct;320:112980.

Hasan A, Morshed M, Memic A, Hassan S, Webster T, Marei H. Nanoparticles in tissue engineering: applications, challenges and prospects. Int J Nanomedicine. 2018 Sep 24;13: 5637-55.

Hawryluk GW, Mothe A, Wang J, Wang S, Tator C, Fehlings MG. An in vivo characterization of trophic factor production following neural precursor cell or bone marrow stromal cell transplantation for spinal cord injury. Stem Cells Dev. 2012 Aug 10;21(12):2222-38.

Hellenbrand DJ, Reichl KA, Travis BJ, Filipp ME, Khalil AS, Pulito DJ, et al . Sustained interleukin-10 delivery reduces inflammation and improves motor function after spinal cord injury. J Neuroinflammation. 2019 Apr 30; 16(1):93.

Hsieh FY, Lin HH, Hsu SH. 3D bioprinting of neural stem cell-laden thermoresponsive biodegradable polyurethane hydrogel and potential in central nervous system repair. Biomaterials. 2015 Dec 1;71:48-57.

Hu JG, Shen L, Wang R, Wang QY, Zhang C, Xi $\mathrm{J}$, et al . Effects of Olig2-overexpressing neural stem cells and myelin basic protein-activated $\mathrm{T}$ cells on recovery from spinal cord injury. Neurotherapeutics. 2012 Apr;9(2):422-45.

Iwasaki M, Wilcox JT, Nishimura Y, Zweckberger K, Suzuki H, Wang J, et al . Synergistic effects of self-assembling peptide and neural stem/ progenitor cells to promote tissue repair and forelimb functional recovery in cervical spinal cord injury. Biomaterials. 2014;35(9):261729.

Iyer NR, Wilems TS, Sakiyama-Elbert SE. Stem cells for spinal cord injury: Strategies to inform differentiation and transplantation. Biotechnol Bioeng. 2017 Feb 01;114(2):245-59.

Kang CE, Poon PC, Tator CH, Shoichet MS. A new paradigm for local and sustained release of therapeutic molecules to the injured spinal cord for neuroprotection and tissue repair. Tissue Eng Part A. 2009 Mar;15(3):595-604.

Karakatsani A, Shah B, Ruiz de Almodovar C. Blood Vessels as Regulators of Neural Stem Cell Properties. Front Mol Neurosci. 2019 Apr 12;12:85-.

Karimi A, Shojaei A, Tehrani P. Mechanical properties of the human spinal cord under the compressive loading. J Chem Neuroanat. 2017 Dec;86:15-8. 
Khaing ZZ, Milman BD, Vanscoy JE, Seidlits SK, Grill RJ, Schmidt CE. High molecular weight hyaluronic acid limits astrocyte activation and scar formation after spinal cord injury. J Neural Eng. 2011 Jul 14;8(4):046033.

Kobelt LJ, Wilkinson AE, McCormick AM, Willits RK, Leipzig ND. Short duration electrical stimulation to enhance neurite outgrowth and maturation of adult neural stem progenitor cells. Ann Biomed Eng. 2014 Oct;42(10): 2164-76.

Koyanagi M, Takahashi J, Arakawa Y, Doi D, Fukuda $\mathrm{H}$, Hayashi $\mathrm{H}$, et al . Inhibition of the Rho/ROCK pathway reduces apoptosis during transplantation of embryonic stem cellderived neural precursors. J Neurosci Res. 2008 Feb 1;86(2):270-80.

Lai Y, Dong C. Therapeutic antibodies that target inflammatory cytokines in autoimmune diseases. Int Immunol. 2016 Apr;28(4):181-8.

Lam J, Lowry WE, Carmichael ST, Segura T. Delivery of iPS-NPCs to the Stroke Cavity within a Hyaluronic Acid Matrix Promotes the Differentiation of Transplanted Cells. Adv Funct Mater. 2014;24(44):7053-62.

Laterza C, Merlini A, De Feo D, Ruffini F, Menon $\mathrm{R}$, Onorati $\mathrm{M}$, et al . iPSC-derived neural precursors exert a neuroprotective role in immune-mediated demyelination via the secretion of LIF. Nat Commun. 2013;4:2597.

Lee JY, Bashur CA, Goldstein AS, Schmidt CE. Polypyrrole-coated electrospun PLGA nanofibers for neural tissue applications. Biomaterials. 2009 Sep 01;30(26):4325-35.

Li J, Mooney DJ. Designing hydrogels for controlled drug delivery. Nat Rev Mater. 2016 Oct 18;1(12):16071.

Li L, El-Hayek YH, Liu B, Chen Y, Gomez E, Wu $\mathrm{X}$, et al . Direct-current electrical field guides neuronal stem/progenitor cell migration. Stem Cells. 2008 Aug;26(8):2193-200.

Li Q, Ford MC, Lavik EB, Madri JA. Modeling the neurovascular niche: VEGF- and BDNF-mediated cross-talk between neural stem cells and endothelial cells: an in vitro study. J Neurosci Res. 2006 Dec;84(8):1656-68.

Li X, Fan C, Xiao Z, Zhao Y, Zhang H, Sun J, et al . A collagen microchannel scaffold carrying paclitaxel-liposomes induces neuronal differentiation of neural stem cells through Wnt/ $\beta$ catenin signaling for spinal cord injury repair. Biomaterials. 2018 Nov 01;183:114-27.

Lima AC, Cunha C, Carvalho A, Ferreira H, Neves NM. Interleukin-6 Neutralization by Antibodies Immobilized at the Surface of Polymeric Nanoparticles as a Therapeutic Strategy for Arthritic Diseases. ACS Appl Mater Interfaces. 2018 Apr 25;10(16):13839-50.

Liu C, Fan L, Xing J, Wang Q, Lin C, Liu C, et al . Inhibition of astrocytic differentiation of transplanted neural stem cells by chondroitin sulfate methacrylate hydrogels for the repair of injured spinal cord. Biomater Sci. 2019; 7(5):1995-2008.

Liu C, Huang Y, Pang M, Yang Y, Li S, Liu L, et al. Tissue-Engineered Regeneration of Completely Transected Spinal Cord Using In- duced Neural Stem Cells and Gelatin-Electrospun Poly (Lactide-Co-Glycolide)/Polyethylene Glycol Scaffolds. PLoS One. 2015;10(3): e0117709.

Liu JMH, Zhang X, Joe S, Luo X, Shea LD. Evaluation of biomaterial scaffold delivery of IL-33 as a localized immunomodulatory agent to support cell transplantation in adipose tissue. J Immunol Regen Med. 2018 Mar 01;1:1-12.

Liu X, Liu J, Zhao S, Zhang H, Cai W, Cai M, et al . Interleukin-4 Is Essential for Microglia/ Macrophage M2 Polarization and LongTerm Recovery After Cerebral Ischemia. Stroke. 2016 Feb;47(2):498-504.

Lobo-Silva D, Carriche GM, Castro AG, Roque S, Saraiva M. Balancing the immune response in the brain: IL-10 and its regulation. J Neuroinflammation. 2016 Nov 24;13(1):297-7.

Loh QL, Choong C. Three-dimensional scaffolds for tissue engineering applications: role of porosity and pore size. Tissue Eng Part B Rev. 2013;19(6):485-502.

Lowry N, Goderie SK, Adamo M, Lederman P, Charniga C, Gill J, et al . Multipotent embryonic spinal cord stem cells expanded by endothelial factors and Shh/RA promote functional recovery after spinal cord injury. Exp Neurol. 2008 Feb;209(2):510-22.

Lu P, Wang Y, Graham L, McHale K, Gao M, Wu $\mathrm{D}$, et al . Long-distance growth and connectivity of neural stem cells after severe spinal cord injury. Cell. 2012;150(6):1264-73.

Madden LR, Mortisen DJ, Sussman EM, Dupras SK, Fugate JA, Cuy JL, et al . Proangiogenic scaffolds as functional templates for cardiac tissue engineering. Proc Natl Acad Sci USA. 2010 Aug 24;107(34):15211-6.

Madl CM, Heilshorn SC. Bioorthogonal Strategies for Engineering Extracellular Matrices. Adv Funct Mater. 2018 Jan 19;28(11): 1706046.

Margul DJ, Park J, Boehler RM, Smith DR, Johnson MA, McCreedy DA, et al . Reducing neuroinflammation by delivery of IL- 10 encoding lentivirus from multiple-channel bridges. Bioeng Transl Med. 2016 Jun;1(2):136-48.

Marquardt LM, Doulames VM, Wang AT, Dubbin K, Suhar RA, Kratochvil MJ, et al . Designer, injectable gels to prevent transplanted Schwann cell loss during spinal cord injury therapy. Sci Adv. 2020 Apr 01;6(14): eaaz1039.

Marquardt LM, Heilshorn SC. Design of Injectable Materials to Improve Stem Cell Transplantation. Curr Stem Cell Rep. 2016 Sept 01; 2(3):207-20.

Mauri E, Negri A, Rebellato E, Masi M, Perale G, Rossi F. Hydrogel-Nanoparticles Composite System for Controlled Drug Delivery. Gels. 2018 Sep 4;4(3):74.

McCreedy DA, Wilems TS, Xu H, Butts JC, Brown CR, Smith AW, et al . Survival, Differentiation, and Migration of High-Purity Mouse Embryonic Stem Cell-derived Progenitor Motor Neurons in Fibrin Scaffolds after Sub-Acute Spinal Cord Injury. Biomater Sci. 2014;2(11):1672-82.
Mitrousis N, Fokina A, Shoichet MS. Biomaterials for cell transplantation. Nat Rev Mater. 2018 Nov 01;3(11):441-56.

Mori S, Maher P, Conti B. Neuroimmunology of the Interleukins 13 and 4. Brain Sci. 2016 Jun 13;6(2):18.

Morrison SJ, Spradling AC. Stem Cells and Niches: Mechanisms That Promote Stem Cell Maintenance throughout Life. Cell. 2008 Jun 13;132(4):598-611.

Moshayedi P, Nih LR, Llorente IL, Berg AR, Cinkornpumin J, Lowry WE, et al . Systematic optimization of an engineered hydrogel allows for selective control of human neural stem cell survival and differentiation after transplantation in the stroke brain. Biomaterials. 2016 Oct 01;105:145-55.

Mosser DM, Edwards JP. Exploring the full spectrum of macrophage activation. Nat Rev Immunol. 2008 Dec;8(12):958-69.

Mothe AJ, Tam RY, Zahir T, Tator CH, Shoichet MS. Repair of the injured spinal cord by transplantation of neural stem cells in a hyaluronan-based hydrogel. Biomaterials. 2013 May 01;34(15):3775-83.

Nakagomi N, Nakagomi T, Kubo S, Nakano-Doi A, Saino O, Takata M, et al . Endothelial cells support survival, proliferation, and neuronal differentiation of transplanted adult ischemia-induced neural stem/progenitor cells after cerebral infarction. Stem Cells. 2009 Sep;27(9):2185-95.

Nazmi A, Mohamed Arif I, Dutta K, Kundu K, Basu A. Neural stem/progenitor cells induce conversion of encephalitogenic $\mathrm{T}$ cells into CD4+-CD25+- FOXP3+ regulatory $\mathrm{T}$ cells. Viral Immunol. 2014 Mar;27(2):48-59.

Nguyen HT, Sapp S, Wei C, Chow JK, Nguyen A, Coursen J, et al . Electric field stimulation through a biodegradable polypyrrole-copolycaprolactone substrate enhances neural cell growth. J Biomed Mater Res A. 2014 Aug; 102(8):2554-64.

Nih LR, Gojgini S, Carmichael ST, Segura T. Dual-function injectable angiogenic biomaterial for the repair of brain tissue following stroke. Nat Mater. 2018 Jul 01;17(7):642-51.

Nih LR, Sideris E, Carmichael ST, Segura T. Injection of Microporous Annealing Particle (MAP) Hydrogels in the Stroke Cavity Reduces Gliosis and Inflammation and Promotes NPC Migration to the Lesion. Adv Mater Weinheim. 2017 Aug 01;29(32):1606471.

Novak ML, Koh TJ. Macrophage phenotypes during tissue repair. J Leukoc Biol. 2013 Mar 15; 93(6):875-81.

O'Brien FJ, Harley BA, Yannas IV, Gibson LJ. The effect of pore size on cell adhesion in collagenGAG scaffolds. Biomaterials. 2005 Feb 01; 26(4):433-41.

Otsuki L, Brand AH. The vasculature as a neural stem cell niche. Neurobiol Dis. 2017 Nov 01; 107:4-14

Papa S, Ferrari R, De Paola M, Rossi F, Mariani A, Caron I, et al . Polymeric nanoparticle system to target activated microglia/macrophages in spinal cord injury. J Control Release. 2014 Jan 28;174:15-26.
Biomaterials to Support Cell-Mediated Repair of the CNS
Cells Tissues Organs 2022;211:655-669 DOI: $10.1159 / 000515351$
667 
Papa S, Rossi F, Ferrari R, Mariani A, De Paola M, Caron I, et al . Selective nanovector mediated treatment of activated proinflammatory microglia/macrophages in spinal cord injury. ACS Nano. 2013 Nov 26;7(11):9881-95.

Park J, Decker JT, Margul DJ, Smith DR, Cummings BJ, Anderson AJ, et al . Local Immunomodulation with Anti-inflammatory Cytokine-Encoding Lentivirus Enhances Functional Recovery after Spinal Cord Injury. Mol Ther. 2018a Jul 5;26(7):1756-70.

Park J, Decker JT, Smith DR, Cummings BJ, Anderson AJ, Shea LD. Reducing inflammation through delivery of lentivirus encoding for anti-inflammatory cytokines attenuates neuropathic pain after spinal cord injury. J Control Release. 2018b Nov 28;290: 88-101.

Park J, Zhang Y, Saito E, Gurczynski SJ, Moore $\mathrm{BB}$, Cummings BJ, et al . Intravascular innate immune cells reprogrammed via intravenous nanoparticles to promote functional recovery after spinal cord injury. Proc Natl Acad Sci USA. 2019 Jul 23;116(30):14947-54.

Parr AM, Kulbatski I, Zahir T, Wang X, Yue C, Keating A, et al . Transplanted adult spinal cord-derived neural stem/progenitor cells promote early functional recovery after rat spinal cord injury. Neuroscience. 2008 Aug 26;155(3):760-70.

Patra JK, Das G, Fraceto LF, Campos EVR, Rodriguez-Torres MP, Acosta-Torres LS, et al. Nano based drug delivery systems: recent developments and future prospects. J Nanobiotechnology. 2018 Sep19;16(1):71.

Piantino J, Burdick JA, Goldberg D, Langer R, Benowitz LI. An injectable, biodegradable hydrogel for trophic factor delivery enhances axonal rewiring and improves performance after spinal cord injury. Exp Neurol. 2006 Oct 01;201(2):359-67.

Piltti KM, Avakian SN, Funes GM, Hu A, Uchida $\mathrm{N}$, Anderson AJ, et al . Transplantation dose alters the dynamics of human neural stem cell engraftment, proliferation and migration after spinal cord injury. Stem Cell Res. 2015 Sep; 15(2):341-53.

Piltti KM, Salazar DL, Uchida N, Cummings BJ, Anderson AJ. Safety of epicenter versus intact parenchyma as a transplantation site for human neural stem cells for spinal cord injury therapy. Stem Cells Transl Med. 2013a Mar; 2(3):204-16.

Piltti KM, Salazar DL, Uchida N, Cummings BJ, Anderson AJ. Safety of human neural stem cell transplantation in chronic spinal cord injury. Stem Cells Transl Med. 2013b Dec;2(12): 961-74.

Pritchard CD, O'Shea TM, Siegwart DJ, Calo E, Anderson DG, Reynolds FM, et al . An injectable thiol-acrylate poly(ethylene glycol) hydrogel for sustained release of methylprednisolone sodium succinate. Biomaterials. 2011 Jan 01;32(2):587-97.

Putnam AJ. The Instructive Role of the Vasculature in Stem Cell Niches. Biomater Sci. 2014 Nov;2(11):1562-73.
Rahman A, Tiwari A, Narula J, Hickling T. Importance of Feedback and Feedforward Loops to Adaptive Immune Response Modeling. CPT Pharmacometrics Syst Pharmacol. 2018 Sep 10;7(10):621-8.

Roitbak T, Li L, Cunningham LA. Neural stem/ progenitor cells promote endothelial cell morphogenesis and protect endothelial cells against ischemia via HIF-1alpha-regulated VEGF signaling. J Cereb Blood Flow Metab. 2008 Sep;28(9):1530-42.

Rossi F, Ferrari R, Papa S, Moscatelli D, Casalini $\mathrm{T}$, Forloni G, et al . Tunable hydrogelnanoparticles release system for sustained combination therapies in the spinal cord. Colloids Surf B Biointerfaces. 2013 Aug 01;108: 169-77.

Ruff CA, Wilcox JT, Fehlings MG. Cell-based transplantation strategies to promote plasticity following spinal cord injury. Exp Neurol. 2012 May;235(1):78-90.

Ruzicka J, Romanyuk N, Hejcl A, Vetrik M, Hruby $M$, Cocks $G$, et al . Treating spinal cord injury in rats with a combination of human fetal neural stem cells and hydrogels modified with serotonin. Acta Neurobiol Exp (Wars). 2013;73(1):102-15

Schwab JM, Zhang Y, Kopp MA, Brommer B, Popovich PG. The paradox of chronic neuroinflammation, systemic immune suppression, autoimmunity after traumatic chronic spinal cord injury. Exp Neurol. 2014;258: 121-9.

Sharpe LA, Daily AM, Horava SD, Peppas NA. Therapeutic applications of hydrogels in oral drug delivery. Expert Opin Drug Deliv. 2014 May 15;11(6):901-15.

Shen Q, Goderie SK, Jin L, Karanth N, Sun Y, Abramova N, et al. Endothelial cells stimulate self-renewal and expand neurogenesis of neural stem cells. Science. 2004 May 28;304(5675): 1338-40.

Shen Q, Wang Y, Kokovay E, Lin G, Chuang SM, Goderie SK, et al . Adult SVZ stem cells lie in a vascular niche: a quantitative analysis of niche cell-cell interactions. Cell Stem Cell. 2008 Sep 11;3(3):289-300.

Sher F, Amor S, Gerritsen W, Baker D, Jackson SL, Boddeke E, et al . Intraventricularly injected Olig2-NSCs attenuate established relapsing-remitting EAE in mice. Cell Transplant. 2012;21(9):1883-97.

Shin JE, Jung K, Kim M, Hwang K, Lee H, Kim $\mathrm{I}-\mathrm{S}$, et al . Brain and spinal cord injury repair by implantation of human neural progenitor cells seeded onto polymer scaffolds. Exp Mol Med. 2018;50(4):39.

Sieminski AL, Gooch KJ. Biomaterial-microvasculature interactions. Biomaterials. $2000 \mathrm{Nov}$ 15;21(22):2232-41.

Singh A, Peppas NA. Hydrogels and scaffolds for immunomodulation. Adv Mater Weinheim. 2014 Oct;26(38):6530-41.

Slotkin JR, Ness JK, Snyder KM, Skiles AA, Woodard EJ, O'Shea T, et al . Sustained Local Release of Methylprednisolone From a ThiolAcrylate Poly(Ethylene Glycol) Hydrogel for
Treating Chronic Compressive Radicular Pain. Spine. 2016 Apr;41(8):E441-8.

Smith DR, Dumont CM, Park J, Ciciriello AJ, Guo A, Tatineni R, et al . Polycistronic Delivery of IL-10 and NT-3 Promotes Oligodendrocyte Myelination and Functional Recovery in a Mouse Spinal Cord Injury Model. Tissue Eng Part A. 2020 Jun;26(11囚12):672-82.

Song S, George PM. Conductive polymer scaffolds to improve neural recovery. Neural Regen Res. 2017 Nov 29;12(12):1976-8.

Stukel JM, Willits RK. Mechanotransduction of Neural Cells Through Cell-Substrate Interactions. Tissue Eng Part B Rev. 2015 Jun 01; 22(3): 173-82.

Stukel JM, Willits RK. The interplay of peptide affinity and scaffold stiffness on neuronal differentiation of neural stem cells. Biomed Mater. 2018 Feb 02;13(2):024102.

Sun J, Zhou W, Ma D, Yang Y. Endothelial cells promote neural stem cell proliferation and differentiation associated with VEGF activated Notch and Pten signaling. Dev Dyn. 2010 Sep 01;239(9):2345-53.

Tang Y, Yu P, Cheng L. Current progress in the derivation and therapeutic application of neural stem cells. Cell Death Dis. 2017 Oct 12; 8(10):e3108.

Tavazoie M, Van der Veken L, Silva-Vargas V, Louissaint M, Colonna L, Zaidi B, et al. A specialized vascular niche for adult neural stem cells. Cell Stem Cell. 2008 Sep 11;3(3):279-88.

Taylor SJ, Rosenzweig ES, McDonald JW3rd, Sakiyama-Elbert SE. Delivery of neurotrophin-3 from fibrin enhances neuronal fiber sprouting after spinal cord injury. J Control Release. 2006 Jul 20;113(3):226-35.

Tetzlaff W, Okon EB, Karimi-Abdolrezaee S, Hill CE, Sparling JS, Plemel JR, et al . A systematic review of cellular transplantation therapies for spinal cord injury. J Neurotrauma. 2011 Aug;28(8):1611-82.

Thompson S, Martínez-Burgo B, Sepuru KM, Rajarathnam K, Kirby JA, Sheerin NS, et al . Regulation of Chemokine Function: The Roles of GAG-Binding and Post-Translational Nitration. Int J Mol Sci. 2017 Aug 03;18(8):1692.

Uchida Y, Yagi Y, Takao M, Tano M, Umetsu M, Hirano S, et al . Comparison of Absolute Protein Abundances of Transporters and Receptors among Blood-Brain Barriers at Different Cerebral Regions and the Blood-Spinal Cord Barrier in Humans and Rats. Mol Pharm. 2020 Jun 1;17(6):2006-20.

Underwood RA, Usui ML, Zhao G, Hauch KD, Takeno MM, Ratner BD, et al . Quantifying the effect of pore size and surface treatment on epidermal incorporation into percutaneously implanted sphere-templated porous biomaterials in mice. J Biomed Mater Res A. 2011 Sep 15;98(4):499-508.

Vadivelu S, Stewart TJ, Qu Y, Horn K, Liu S, Li Q, et al . NG2+ progenitors derived from embryonic stem cells penetrate glial scar and promote axonal outgrowth into white matter after spinal cord injury. Stem Cells Transl Med. 2015 Apr;4(4):401-11. 
Vandghanooni S, Eskandani M. Electrically conductive biomaterials based on natural polysaccharides: Challenges and applications in tissue engineering. Int J Biol Macromol. 2019 Dec 01;141:636-62.

Wang J, Zheng J, Zheng Q, Wu Y, Wu B, Huang $\mathrm{S}$, et al . FGL-functionalized self-assembling nanofiber hydrogel as a scaffold for spinal cord-derived neural stem cells. Mater Sci Eng C Mater Biol Appl. 2015 Jan 01;46:140-7.

Wang L, Wei FX, Cen JS, Ping SN, Li ZQ, Chen $\mathrm{NN}$, et al . Early administration of tumor necrosis factor-alpha antagonist promotes survival of transplanted neural stem cells and axon myelination after spinal cord injury in rats. Brain Res. 2014 Aug 05;1575:87-100.

Wang S, Bates J, Li X, Schanz S, Chandler-Militello D, Levine C, et al . Human iPSC-derived oligodendrocyte progenitor cells can myelinate and rescue a mouse model of congenital hypomyelination. Cell Stem Cell. 2013 Feb 7; 12(2):252-64.

Wang TY, Bruggeman KF, Kauhausen JA, Rodriguez AL, Nisbet DR, Parish CL. Functionalized composite scaffolds improve the engraftment of transplanted dopaminergic progenitors in a mouse model of Parkinson's disease. Biomaterials. 2016;74:89-98.
Wang Y, Li Z, Ouyang J, Karniadakis GE. Controlled release of entrapped nanoparticles from thermoresponsive hydrogels with tunable network characteristics. Soft Matter. 2020 Apr 23;16(20):4756-66.

Wang ZZ, Sakiyama-Elbert SE. Matrices, scaffolds \& carriers for cell delivery in nerve regeneration. Exp Neurol. 2019 Sep 01;319: 112837.

Willis CM, Nicaise AM, Peruzzotti-Jametti L, Pluchino S. The neural stem cell secretome and its role in brain repair. Brain Res. 2020 2020/02/15/;1729:146615.

Xu B, Zhao Y, Xiao Z, Wang B, Liang H, Li X, et al. A Dual Functional Scaffold Tethered with EGFR Antibody Promotes Neural Stem Cell Retention and Neuronal Differentiation for Spinal Cord Injury Repair. Adv Healthc Mater. 2017 Feb 24;6(9):1601279.

Xu R, Feyeux M, Julien S, Nemes C, Albrechtsen M, Dinnyés A, et al . Screening of bioactive peptides using an embryonic stem cell-based neurodifferentiation assay. AAPS J. 2014 May; 16(3):400-12.

Xuan FL, Chithanathan K, Lilleväli K, Yuan X, Tian L. Differences of Microglia in the Brain and the Spinal Cord. Front Cell Neurosci. 2019;13:504.
Yoon H, Walters G, Paulsen AR, Scarisbrick IA. Astrocyte heterogeneity across the brain and spinal cord occurs developmentally, in adulthood and in response to demyelination. PLoS One. 2017;12(7):e0180697.

Zhang Q, Gong H, Gao W, Zhang L. Recent Progress in Capturing and Neutralizing Inflammatory Cytokines. CCS Chem. 2020 Jun 1; 2(3):376-89.

Zholudeva LV, Iyer N, Qiang L, Spruance VM, Randelman ML, White NW, et al . Transplantation of Neural Progenitors and V2a Interneurons after Spinal Cord Injury. J Neurotrauma. 2018 Dec 15;35(24):2883-903.

Zhu R, Sun Z, Li C, Ramakrishna S, Chiu K, He L. Electrical stimulation affects neural stem cell fate and function in vitro. Exp Neurol. 2019 Sep 01;319:112963.

Zuidema JM, Gilbert RJ, Gottipati MK. Biomaterial Approaches to Modulate Reactive Astroglial Response. Cells Tissues Organs. 2018 Dec 05;205(5-6):372-95.

Zweckberger K, Ahuja CS, Liu Y, Wang J, Fehlings MG. Self-assembling peptides optimize the post-traumatic milieu and synergistically enhance the effects of neural stem cell therapy after cervical spinal cord injury. Acta Biomater. 2016;42:77-89. 